\title{
Uma educação para um mundo em constante transformação: os desafios da formação de professores
}

\author{
Anelise Pereira SiHLeR ${ }^{1}$ \\ Bernadete Moreira Pessanha Cordeiro² \\ SANDra Mara SOUZa BESSA ${ }^{3}$
}

Resumo: Este artigo tem por objetivo apresentar caminhos que possibilitem refletir sobre a formação de professores e repensá-la em uma sociedade em constante mudança. Por meio de uma revisão integrativa a partir de fontes bibliográficas e dados institucionais, procurou-se reunir pressupostos teóricos, instrumentos, documentos e perspectivas, mundiais e nacionais, que poderão colaborar para as Instituições de Ensino Superior no desafio de construir uma docência que, apesar de imersa nas tecnologias, seja mais humana.

Palavras-chave: Formação de professores. Educação. Qualidade na docência.

\section{Education for a constant transformation world: the challenges of teacher training}

\begin{abstract}
This article aims to present ways that make it possible to reflect and rethink teacher education in a constantly changing society. Through an integrative review, from bibliographic sources and institutional data, we sought to gather theoretical assumptions, instruments, documents and perspectives, worldwide and national, that can collaborate with Higher Education Institutions in the challenge of building a teaching that despite immersed in technologies is more humane.

Keywords: Teacher training. Education. Quality in teaching.

\section{Educación para un mundo en constante transformación: los desafíos para la formación de profesores}

Resumen: Este artículo tiene como objetivo presentar formas que permitan reflexionar y repensar la formación del profesorado en una sociedad en constante cambio. A través de una revisión integradora, de fuentes bibliográficas y datos institucionales, buscamos reunir presupuestos teóricos, instrumentos, documentos y perspectivas, a nivel mundial y nacional, que puedan colaborar con las instituciones de educación superior en el desafío de construir una eduación que, a pesar de inmerso en tecnologias, sea más humana.

Palabras clave: Formación docente. Educación. Calidad en la enseñanza. 


\section{Introdução}

As demanda, os desafios e as exigências da sociedade contemporânea impõem às Instituições de Ensino Superior a necessidade de transformar a formação de professores para atuarem em um cenário futuro em que apenas há uma certeza: a tecnologia estará lá.

Para onde deve ir à formação? Quais demandas, desafios e exigências devem ser respondidos? Quais dados e informações podem auxiliar no processo de construção de uma nova docência? Quais competências espera-se desse novo docente?

Diante dessas e de outras perguntas que podem ser feitas a partir delas é que este artigo buscou reunir pressupostos teóricos, instrumentos, documentos e perspectivas, internacionais e nacionais, que poderão colaborar para as Instituições de Ensino Superior na elaboração de uma nova proposta de formação de professores.

Nesse sentido, após explorar a relação existente entre educação, sociedade e docência, bem como abordar a qualidade da docência e a qualidade da aprendizagem, apresentam-se as perspectivas internacionais e nacionais no âmbito da educação, finalizando com algumas possibilidades para repensar a formação.

É importante ressaltar que não há pretensão de se esgotar o tema, mas sim abrir caminhos para reflexão e diálogos que auxiliem na construção de ações a serem tomadas.

\section{Educação, sociedade e docência}

Vivencia-se um tempo histórico impregnado por incertezas, tensões e contradições que demarcam a necessidade de um novo olhar da educação sobre o processo de formação do ser humano. Essa relação existente entre educação e sociedade sempre justificou os desafios e as exigências da formação de professores, impulsionando, na atualidade, uma revisão dos paradigmas vigentes.

Esse cenário impõe repensar o papel da docência e o impacto de sua atuação para que se alcancem, de fato, as mudanças tão necessárias na educação escolar brasileira. Refletir sobre o papel do professor passa, portanto, por discutir como se dá sua relação com a sociedade, com o Estado, com as outras instituições que compõem o tecido social e ainda com as formas de ver e trabalhar a aprendizagem nesse contexto complexo. Ou seja, refletir sobre esse papel implica refletir sobre a formação do próprio sujeito. A respeito da formação de sujeitos na Educação Superior, Monfredini (2016, p. 16) afirma:

Com base nessas reflexões, entende-se que a Universidade, ao desenvolver pesquisa, ensino e extensão, pode se constituir num espaço qualificado visando a formação de sujeitos capazes de cons- 
tituírem a narrativa da própria vida, do tempo e do espaço em que vivem. A realização desta possibilidade implica num amplo e complexo movimento de integrar alunos, professores pesquisadores, os governos, os movimentos sociais em relações democráticas, que propiciem experiências coletivas de autonomia e autodeterminação. Implica na criação de espaços que integrem os diferentes conhecimentos, saberes e afetos dos envolvidos. Tomada da perspectiva social mais ampla, implica o desafio de que os envolvidos se saibam sujeitos.

Esse contexto leva a pensar, por exemplo, como se pode alcançar uma boa formação sem passar pelas experiências de vida dos atores sociais envolvidos nesse processo de construção da identidade enquanto professores em formação e professores formadores. Isso leva a questões como: de que maneira os cursos de licenciatura permitem refletir sobre essas mudanças? Em que medida são propiciadas vivências práticas que levem à adoção desse novo paradigma? Como suprir o que a história de vida desses professores em formação não lhes deu? Qual é o papel das instituições de Educação Superior nesse contexto?

Para responder a todas essas questões, pode-se recorrer a numerosas teorias que tratam da contextualização do ensino, da inserção de tecnologias em educação e da revisão das práticas adotadas nas escolas. Apesar das também inúmeras proposições teóricas, a realidade se repete insistente e teimosamente, mantendo um círculo vicioso, na medida em que a formação oferecida na Educação Superior mantém as práticas conservadoras já tão bem conhecidas em contraponto com o que se apregoa teoricamente.

O que ocorre realmente é que as Instituições de Ensino Superior (IES), que deveriam tomar para si a vanguarda das mudanças que se quer na educação, tendo em vista que boa parte dos professores adota as práticas que experienciam como alunos, não o fazem, perpetuando esse movimento dentro de si mesmas e para além de seus muros, em uma espiral de conservadorismo e paralisia. Nesse sentido, abandonam seu papel precípuo como instituição que assume o compromisso em promover o avanço do conhecimento e das técnicas aplicadas em diversos campos do saber.

As IES, dessa forma, não têm atendido às expectativas de ser espaço da invenção e da descoberta, compromissadas com a busca de novos conhecimentos, sendo, assim, local de produção de inovações na própria história da humanidade. Nessa lógica, é de suma importância que as IES tomem para si a responsabilidade pelo desenvolvimento da educação do país, pois, além de realizar ensino e pesquisa, devem produzir cultura, influenciando a sociedade na qual está inserida e sendo influenciada por ela. A esse respeito, Roggero (2016, p. 31) afirma que:

Os processos de alienação e o pensamento fragmentário frequentemente observados na educação superior exigem a busca de al- 
ternativas que deem maior consistência ao processo educacional. Ainda que existam ilhas de excelência, não me parece digno para o desenvolvimento de um país que estejam tão isoladas.

Como espaço privilegiado de formação para a docência, as IES têm um papel estratégico e fundamental para o alcance das metas educacionais e a superação do status atual em que se encontra a educação. Deve-se, portanto, compreender os cursos de formação como espaço de pensamento livre, plural, crítico, em que as diferentes visões se confrontam em amplo movimento de construção do conhecimento.

Assim, estabelecem-se novas possibilidades de diálogo e de aprendizagens que podem gerar uma nova forma de ser e de estar no mundo como docentes. No entanto, não se pode esquecer o caráter mercadológico e de ranqueamento a que as instituições são submetidas, gerando tensões e obrigações que nem sempre estão alinhadas com a qualidade das aprendizagens ou mesmo com a geração de novos conhecimentos.

O docente assim se torna elemento constitutivo e imprescindível para a qualidade do processo educativo. A sua atuação passa a ser sinônimo de ação consciente para o desenvolvimento do ser humano por meio da educação a partir de uma nova maneira de olhar a realidade e o conhecimento possível, em uma dinâmica que permita viver em atitude curiosa, investigativa e proativa, em uma relação não competitiva, mas cooperativa, desprovida de certezas absolutas, ao viver, conhecer e propor novas formas de ensinar e de aprender que considerem as premências de uma época marcada pela fluidez e pela incerteza.

\section{A qualidade da docência e a qualidade das aprendizagens}

Evidências mostram que, entre os fatores que podem ser controlados pela política educacional, os professores são os que têm maior peso na determinação do desempenho dos alunos. Não é difícil constatar o impacto que os docentes causam na escolha profissional de estudantes adolescentes, quando estes deixam o Ensino Médio, os quais se direcionam para áreas ligadas aos professores com quem estabeleceram laços que geraram aprendizagens.

Os dados da educação nacional, no entanto, apresentam uma realidade bastante grave no que diz respeito à formação desse docente:

As formações inicial e continuada dos professores são igualmente decisivas para professores bem preparados e engajados. No Brasil, 37,8\% dos docentes não possuíam titulação em grau superior compatível com as disciplinas que lecionavam nos Anos Finais do Ensino Fundamental, em 2018 (GOTTI, 2019, s/p). 
Longe, portanto, de alcançar as metas educacionais para a formação de professores no que se refere à formação inicial requerida para atuar com determinadas áreas do conhecimento, enfrenta-se o ainda o problema de não reconhecer a qualidade da formação dada a esses professores:

Como se isso não bastasse, diversas pesquisas retratam que, em sua grande maioria, os cursos de formação inicial no Brasil, tanto em Pedagogia quanto em Licenciaturas específicas, estão pouco focados em técnicas de "como ensinar" os alunos. A meta 15 do Plano Nacional de Educação prevê a garantia de uma política nacional de formação dos profissionais da educação e a estratégia 15.6, por sua vez, enfatiza a necessidade de promover a reforma curricular dos cursos de licenciatura e estimular a renovação pedagógica, de forma a assegurar o foco no aprendizado do aluno (GOTTI, 2019, s/p).

Essas informações remetem à necessidade de investimento e de melhorias na formação para a docência com vistas à qualificação do processo educativo na Educação Básica. O reconhecimento de que é preciso quebrar o ciclo de má-formação e má atuação nos cursos de licenciatura é fundamental para que se altere o quadro atual da educação brasileira.

Observando os dados do Anuário Brasileiro da Educação Básica 2019, do Todos pela Educação, evidencia-se a insatisfação de professores com a própria profissão: $49 \%$ dos professores ouvidos na Pesquisa Profissão Docente, feita pelo IBOPE, Todos pela Educação e Fundação Itaú Social, em 2018, afirmam que não recomendariam sua profissão a um jovem. Por outro lado, as razões que justificam a recomendação da carreira estão muito relacionadas às justificativas apresentadas pelos professores quando tratam dos fatores que os levaram a escolher a profissão, como impacto social, transmissão de conhecimento e realização pessoal que proporciona. Esses dados evidenciam uma necessidade urgente de se investir na captação para a carreira docente que só se dará com melhores condições de trabalho e valorização profissional (IBOPE INTELIGÊNCIA, 2019).

Segundo Gatti (2017), da forma como estão organizadas, as licenciaturas não estão estruturadas para formar um bom professor. Elas apresentam, em sua maioria, uma formação genérica e superficial que não prepara seus egressos para responder às exigências de atuação do docente na contemporaneidade. Não é difícil compreender que muito do que os professores trazem para a sua atuação está relacionado com os modelos de professores que têm.

Se os professores formadores atuam de maneira conservadora sem observar as necessidades, os desafios e as dificuldades desse fazer pedagógico na atualidade, não há como alterar a atuação do docente da Educação Básica. Dito de outra forma, é preciso compreender plenamente o que se propõe para a Educação Básica para que possa discutir efetivamente quais os caminhos a tomar que objetivem for- 
mar os professores que atuarão nesse nível de ensino com toda a sua diversidade. Sem essa ação consciente e intencional em direção a uma formação efetiva para determinados fins, todas as discussões não passarão de elucubrações sem sentido.

Há que se fazer uma verdadeira revolução no que diz respeito à práxis docente com vistas a alcançar a qualidade que se pretende para a educação nacional, explicitadas nas diferentes legislações e diretrizes curriculares. As expectativas são múltiplas e exigem de fato outro tipo de formação. Gatti (2017, p. 1153), sobre o tema, afirma:

Para tanto, professores são instados a ter como responder em sua seara de trabalho por uma formação para seus alunos que os habilite a compreender o mundo, a natureza, a vida social, aprendendo a fazer escolhas com base em conhecimentos e valores. Aos profissionais do magistério, é necessária uma formação para a comunicação efetiva professores-alunos, para a escuta efetiva alunos-professores, para o diálogo pedagógico visando à construção e constituição de aprendizagens. São formas de agir que exigem aprendizagem e se sustentam em conhecimentos e práticas culturais da didática e das metodologias relativas às relações educacionais intencionais recheadas com os conteúdos relevantes à vida humana e coletiva.

A transição entre a escola convencional, com a qual se lida há tanto tempo, e a escola que se deseja requer uma mudança de mentalidade: nova consciência, nova postura, novas habilidades e novos conhecimentos. E isso não pode se restringir ao licenciando, mas deve se aplicar primeiramente aos seus formadores, os quais devem refletir sobre quais são as questões centrais que vão nortear os currículos dos cursos de formação de professores e como se dará o diálogo da formação com a realidade imposta.

Dessa maneira, é imperiosa e inadiável a adoção de uma postura inovadora da instituição que considere as realidades locais, regionais, nacionais e internacionais por meio da proposição de novos projetos fundamentados na dialogia, na mediação, na pesquisa e na aplicação de conhecimentos teóricos a uma realidade que está posta. Para se construir esse espaço de inovação e de ruptura, é preciso que se tenha claro que a aprendizagem se constitui mais como processo de transformação do que mera acumulação de conteúdos descontextualizados.

As IES devem promover em seus núcleos de formação as condições para que se discutam, revejam e reconstruam os olhares sobre essa formação para a docência. É fulcral aqui pensar sobre a necessidade de se instigar no licenciando a consciência de sua responsabilidade por sua autoformação como estratégia de autoconhecimento que gera a formulação de significados para as ideologias, os valores e os princípios que constituirão a identidade desse professor em construção. 
Rever sua história de vida, com todos os percursos, os encontros e os desencontros, as motivações e os obstáculos desse processo de se fazer docente, permite a apropriação de um saber que advém do compartilhamento, da troca com o outro, que tem muito a dizer, mas não sozinho, e sim na interação com o que já se pensa, conhece, vivencia. Essa postura contribui para que se possa efetivamente buscar, a partir dessa dialogia, novas possibilidades de aprendizagem para si mesmo e para o outro com quem interagirá ao longo de sua trajetória como docente.

A qualidade da docência e da aprendizagem estabelece uma relação direta com as redes de interação multidirecionais (estudante-estudante, estudante-professor, estudante-professor-mundo-conhecimento). E é no "com-partilhamento" dessa experiência que se vislumbra a aula como espaço de construção coletiva e colaborativa que é determinante para o sucesso do processo educativo. Supera-se, assim, a visão tradicional, instrucionista, e compreendem-se todas as dimensões do ser humano, sua corporeidade, sua emocionalidade e sua espiritualidade. Em diálogo permanente, estabelece-se a interação entre professor, aluno, instrumentos e tecnologias por meio de situações de ensino e aprendizagem problematizadoras e enriquecedoras.

Todas essas possibilidades impõem uma redefinição do papel da Educação Superior como parte de um todo complexo que traz implicações para a sustentabilidade do planeta e a qualidade de vida da humanidade.

\section{Perspectivas mundiais no âmbito da educação}

A preocupação com a qualidade de vida humana e a erradicação da pobreza não se circunscreve a um país ou região, mas se trata de uma preocupação mundial. Entre as ações que permeiam as discussões para solucionar as graves crises que assolam as mais diferentes regiões do mundo está, sem dúvida, a educação.

As pautas de discussão trazem à baila vários dos pontos sobre os quais se refletiu até aqui e tantos outros fundamentais para a busca de soluções aos problemas que enfrentados no Brasil. São muitos os documentos que tratam das demandas atuais para a educação; assim, serão tratados aqui, especificamente, três deles: Agenda 2030 da ONU, Declaração de ICHEON e Educação 2030 da OCDE.

Já no preâmbulo da Agenda 2030, a ONU anuncia que se trata de um plano de ação para as pessoas, o planeta e a prosperidade, o qual intenciona fortalecer a paz universal com mais liberdade. Evidencia-se a necessidade de se erradicar a pobreza em todas as suas formas e dimensões, incluindo a pobreza extrema. Salienta-se que esse é o maior desafio global e um requisito indispensável para o desenvolvimento sustentável, como se pode ver na Figura 1. 
Figura 1 - Desenvolvimento sustentável.

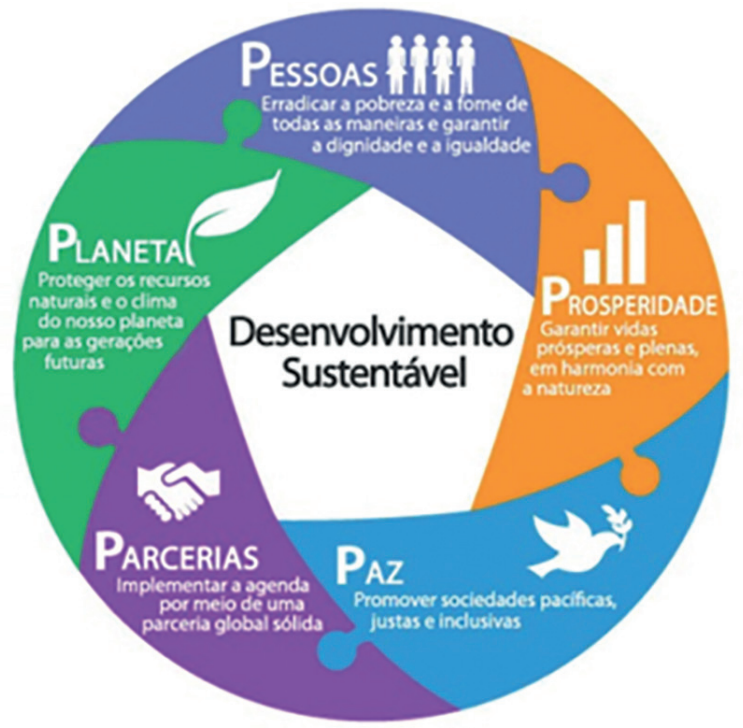

Fonte: Plataforma Agenda 2030.

O documento indica os inúmeros problemas e desafios a serem enfrentados. No entanto, não se trata de uma visão pessimista da realidade. A educação é vista como oportunidade a ser aproveitada:

Este é também, no entanto, um momento de enorme oportunidade. Um progresso significativo foi feito no cumprimento de muitos desafios ao desenvolvimento. Dentro da geração passada, centenas de milhões de pessoas emergiram da pobreza extrema. $\mathrm{O}$ acesso à educação aumentou consideravelmente tanto para meninos quanto para meninas. A disseminação da informação e das tecnologias da comunicação e interconectividade global tem um grande potencial para acelerar o progresso humano, para eliminar o fosso digital e para o desenvolvimento de sociedades do conhecimento, assim como a inovação científica e tecnológica em áreas tão diversas como medicina e energia (ONU, 2015, s/p).

O documento elenca uma série de objetivos a serem alcançados até 2030. São compromissos que se relacionam com a erradicação da fome e da violência, com o empoderamento feminino, o cuidado com a infância, a atenção ao meio ambiente e também a educação. Assim como outros tantos documentos que trazem belas discussões e reflexões acerca das necessidades mundiais, vivencia-se um movimento extremamente oposto no Brasil nesse momento: diminuem-se os investimentos em Educação Básica e Superior; cresce o desmatamento; e os 
direitos humanos são desconsiderados. Há, portanto, não só no Brasil, como em tantos outros lugares do mundo, uma lacuna entre o que se deseja e os caminhos percorridos para se chegar lá.

No que tange ao objetivo 4, "Assegurar a educação inclusiva e equitativa e de qualidade, e promover oportunidades de aprendizagem ao longo da vida para todos", chama atenção o papel dado à educação que deve ser inclusiva, equitativa e de qualidade. O documento aponta a necessidade de adequação urgente do que se faz hoje e indica, de forma muito clara, a necessidade de se investir na formação de professores. Propõe-se:

4.1 Até 2030, garantir que todas as meninas e meninos completem o ensino primário e secundário livre, equitativo e de qualidade, que conduza a resultados de aprendizagem relevantes e eficazes

4.2 Até 2030, garantir que todos as meninas e meninos tenham acesso a um desenvolvimento de qualidade na primeira infância, cuidados e educação pré-escolar, de modo que eles estejam prontos para o ensino primário

4.3 Até 2030, assegurar a igualdade de acesso para todos os homens e mulheres à educação técnica, profissional e superior de qualidade, a preços acessíveis, incluindo universidade

4.4 Até 2030, aumentar substancialmente o número de jovens e adultos que tenham habilidades relevantes, inclusive competências técnicas e profissionais, para emprego, trabalho decente e empreendedorismo

4.5 Até 2030, eliminar as disparidades de gênero na educação e garantir a igualdade de acesso a todos os níveis de educação e formação profissional para os mais vulneráveis, incluindo as pessoas com deficiência, povos indígenas e as crianças em situação de vulnerabilidade

4.6 Até 2030, garantir que todos os jovens e uma substancial proporção dos adultos, homens e mulheres estejam alfabetizados e tenham adquirido o conhecimento básico de matemática

4.7 Até 2030, garantir que todos os alunos adquiram conhecimentos e habilidades necessárias para promover o desenvolvimento sustentável, inclusive, entre outros, por meio da educação para o desenvolvimento sustentável e estilos de vida sustentáveis, direitos humanos, igualdade de gênero, promoção de uma cultura de paz e não violência, cidadania global e valorização da diversidade cultural e da contribuição da cultura para o desenvolvimento sustentável 4.a Construir e melhorar instalações físicas para educação, apropriadas para crianças e sensíveis às deficiências e ao gênero, e que proporcionem ambientes de aprendizagem seguros e não violentos, inclusivos e eficazes para todos

4.b Até 2020, substancialmente ampliar globalmente o número de bolsas de estudo para os países em desenvolvimento, em particular os países menos desenvolvidos, pequenos Estados insulares em desenvolvimento e os países africanos, para o ensino supe- 
rior, incluindo programas de formação profissional, de tecnologia da informação e da comunicação, técnicos, de engenharia e programas científicos em países desenvolvidos e outros países em desenvolvimento

4.c Até 2030, substancialmente aumentar o contingente de professores qualificados, inclusive por meio da cooperação internacional para a formação de professores, nos países em desenvolvimento, especialmente os países menos desenvolvidos e pequenos Estados insulares em desenvolvimento (ONU, 2015, s/p).

Na mesma linha, há o documento Educação 2030: Declaração Incheon e Marco da Ação de Educação, resultado do Fórum Mundial de Educação 2015, em Incheon, na Coreia do Sul, entre 19 e 22 de maio de 2015, organizado pela UNESCO com o UNICEF, o Banco Mundial, o UNFPA, o PNUD, a ONU Mulheres e o ACNUR. O Fórum contou com mais de 1.600 participantes de 160 países, incluindo mais de 120 ministros, chefes e membros de delegações, líderes de agências e funcionários de organizações multilaterais e bilaterais, além de representantes da sociedade civil, da profissão docente, do movimento jovem e do setor privado. No Fórum, adotaram a Declaração de Incheon para a Educação 2030, que estabelece uma nova visão para a educação para os próximos 15 anos.

A Declaração de Incheon traz em seu próprio título o objetivo da Agenda proposta pela ONU: Rumo a uma educação de qualidade inclusiva e equitativa e à educação ao longo da vida para todos. E novamente chama atenção para o destaque à educação inclusiva, equitativa e de qualidade. A declaração reconhece a educação como elemento-chave para atingir o pleno emprego e a erradicação da pobreza.

Em seu bojo traz indicações muito claras do que se espera da educação e do quanto se precisa investir em novos insumos para obter os resultados desejados. Não se esqueceram do papel do professor nesse processo que deve ser empoderado, valorizado e treinado. Aqui também fica evidente que não se alcançam resultados positivos sem considerar a docência:

Comprometemo-nos com uma educação de qualidade e com a melhoria dos resultados de aprendizagem, o que exige o reforço de insumos e processos, além da avaliação de resultados de aprendizagem e de mecanismos para medir o progresso. Garantiremos que professores e educadores sejam empoderados, recrutados adequadamente, bem treinados, qualificados profissionalmente, motivados e apoiados em sistemas que disponham de bons recursos e sejam eficientes e dirigidos de maneira eficaz. A educação de qualidade promove criatividade e conhecimento e também assegura a aquisição de habilidades básicas em alfabetização e matemática, bem como habilidades analíticas e de resolução de problemas, habilidades de alto nível cognitivo e habilidades interpessoais e sociais. Além disso, ela desenvolve habi- 
lidades, valores e atitudes que permitem aos cidadãos levar vidas saudáveis e plenas, tomar decisões conscientes e responder a desafios locais e globais por meio da educação para o desenvolvimento sustentável (EDS) e da educação para a cidadania global (ECG). [...] (UNESCO, 2016, p. IV, grifos nossos).

Essa perspectiva pressupõe um amplo conjunto de conhecimentos, habilidades, atitudes e valores em ação:

- Concepção dos estudantes como agentes de mudança.

- Necessidade de conhecimentos, habilidades, atitudes e valores para atender a demandas complexas e aplicar o conhecimento em circunstâncias desconhecidas e em andamento.

- Criação de condições para que a aprendizagem possa ir além das disciplinas. Os estudantes devem "conectar pontos" (mobilizar saberes).

- Resolução de problemas práticos.

- Pensamento sistêmico.

Como pode se verificar, são muitas as competências a serem trabalhadas na formação desse cidadão que deve acompanhar todas as demandas de um novo cenário social bastante diverso. Segundo Maria Helena Guimarães (FRANÇA, 2019, s/p), ex-secretária executiva do Ministério da Educação:

As competências do século XXI dizem respeito a formar cidadãos mais críticos, com capacidade de aprender a aprender, de resolver problemas, de ter autonomia para a tomada de decisões, cidadãos que sejam capazes de trabalhar em equipe, respeitar o outro, o pluralismo de ideias, que tenham a capacidade de argumentar e defender seu ponto de vista. [...] A sociedade contemporânea impõe um novo olhar a questões centrais da educação, em especial: o que aprender, para que aprender, como ensinar e como avaliar o aprendizado.

O Learning Compass 2030, proposto pela OCDE, define os conhecimentos, as habilidades, as atitudes e os valores que os alunos precisam para realizar seu potencial e contribuir para o bem-estar de suas comunidades e do planeta. Constitui-se, portanto, em outro documento que ratifica a intenção internacional de apresentar um novo olhar sobre a educação e a forma como se está preparando as gerações em idade escolar

Os três documentos mostram que o desafio de preparar uma geração para a vida, para toda a vida, requer do docente não só o conhecimento da realidade local em que está inserido, mas também a sua participação no enfretamento dos problemas sociais de sua comunidade e, consequentemente, do mundo. A partir daí ele terá as condições para falar sobre a verdadeira postura do cidadão na sociedade. 
Só a partir de sua prática, ele poderá influenciar outros para que também possam influenciar o mundo. Para isso, precisa perceber o valor da inserção social de seus alunos, enquanto ainda frequentadores dos ambientes escolar e acadêmico.

\section{Perspectivas nacionais no âmbito da educação}

Assim como acontece no âmbito internacional, no Brasil a questão da educação e da formação dos professores também tem sido pauta recorrente e preocupante, tendo em vista que os resultados não têm se mostrado positivos como se espera há tanto tempo. Embora se tenha uma base teórica bastante fortalecida e uma legislação com uma agenda promissora para a educação, ainda se está longe de chegar ao que se deseja.

Entre os inúmeros problemas enfrentados destacam-se: resultados insuficientes dos estudantes (desigualdades aumentaram), baixa qualidade da formação de professores, currículos extensos que não oferecem atividades práticas, poucos cursos com aprofundamento da formação na Educação Infantil e no ciclo de alfabetização, estágios curriculares sem planejamento e sem vinculação clara com a escola.

As perspectivas das políticas atuais também não se mostram capazes de reverter a situação, especialmente ao pensar nos cortes para a educação, nos cortes orçamentários para os próximos 20 anos, no foco das ações do Ministério da Educação que se distanciam cada vez mais das metas previstas no PNE, na precarização da Educação Superior etc. À revelia do cenário político, entretanto, cabe a análise, mesmo que breve, de documentos importantes que podem nortear os caminhos para a formação de professores em um futuro próximo.

Tendo em vista o pressuposto da importância da formação de professores para que se alcancem de fato as proposições para a educação em um futuro próximo, pois 2030 está aí, o Brasil, em consonância com as perspectivas internacionais, propõe em seu Plano Nacional de Educação metas bastante ambiciosas, emboras imprescindíveis, para que se alcance a transformação desejada.

A meta 15 do PNE (vigente desde 2014), que trata dos Profissionais de Educação, prevê:

Garantir, em regime de colaboração entre a União, os Estados, o Distrito Federal e os Municípios, no prazo de 1 (um) ano de vigêncis deste PNE, política nacional de formação dos profissionais da educação de que tratam os incisos I, II e III do caput do art. 61 da Lei $\mathrm{n}^{\circ}$ 9394, de 20 de dezembro de 1996, assegurado que todos os professores e as professoras da educação básica possuam formação específica de nível superior, obtida em curso de licenciatura na área de conhecimento em que atuam (BRASIL, 2014, p. 12). 
No entanto, a realidade atual mostra que essa meta está longe de ser alcançada. Alvarez (2016, s/p) explicita que "Ainda que não se possa colocar nas costas dos professores toda a responsabilidade sobre a qualidade da educação [...], é consenso em pesquisas internacionais que o docente é o fator principal para obtê-la". Dos 100\% pretendidos, apenas 50,6\% têm a formação prevista.

E é importante salientar que se está tratando apenas de dados estatísticos que não medem a qualidade. Desses $50,6 \%$, boa parte não está qualificada para atender às expectativas de atuação que se quer para a Educação Básica nos moldes previstos nos documentos internacionais ou nacionais. Da mesma forma, a meta 16 do PNE prevê:

Formar, em nível de pós-graduação, 50\% (cinquenta por cento) dos professores da educação básica até o último ano de vigência deste PNE, e garantir a todos(as) os(as) profissionais da educação básica formação continuada em sua área de atuação, considerando as necessidades, demandas e contextualizações dos sistemas de ensino (BRASIL, 2014, p. 12).

Desses $50 \%$ previstos, apenas 30,2\% fizeram pós-graduação. Não se pode afirmar, portanto, que está havendo sucesso no alcance das metas previstas, o que tende a piorar com os cortes na educação, nas bolsas de pesquisa e nos programas de pós-graduação feitos pelo atual governo. Segundo Alvarez (2016), a ausência de uma política efetiva que incentive a formação para a docência daqueles já em exercício - a formação continuada - e a formação para novos docentes se conjuga com a falta de qualidade de muitos cursos de licenciatura e com a baixa atratividade da carreira. Ao observar o número de matrículas de estudantes na Educação Superior, é confirmada essa realidade (Figura 2).

Dos matriculados na Educação Superior, apenas 20\% se propuseram a fazer uma licenciatura, dado que ratifica a pouca atratividade da docência que se relaciona diretamente com a desvalorização profissional, as condições de trabalho e os salários (Figura 3). A escassez de professores já é um problema real em algumas regiões do Brasil e que tende a se agravar nos próximos anos. Que soluções serão dadas a esse problema?

Dos estudantes matriculados na Educação Superior, a maior parte é de mulheres, em universidades, em instituições privadas e na modalidade presencial (Figura 4). Esse perfil permite planejar de forma mais adequada onde e como investir na formação de professores de maneira mais apropriada, visto que não há possibilidade de qualificação desse processo sem um olhar atento do Estado como órgão que planeja, controla, acompanha e avalia a educação nacional.

Nesse contexto em que as responsabilidades são compartilhadas entre os setores privado e público, todos estão conscientes de que se forma uma comunidade de destino, ou seja, as ações e as decisões tomadas têm impacto sobre o 
mundo em que se vive. A proposta aqui é refletir sobre o impacto de ações que viabilizem uma formação adequada de professores, na perspectiva de que estes são os atores sociais mais propícios a transformar a educação.

Figura 2 - Número de matrículas de estudantes na Educação Superior (2017).

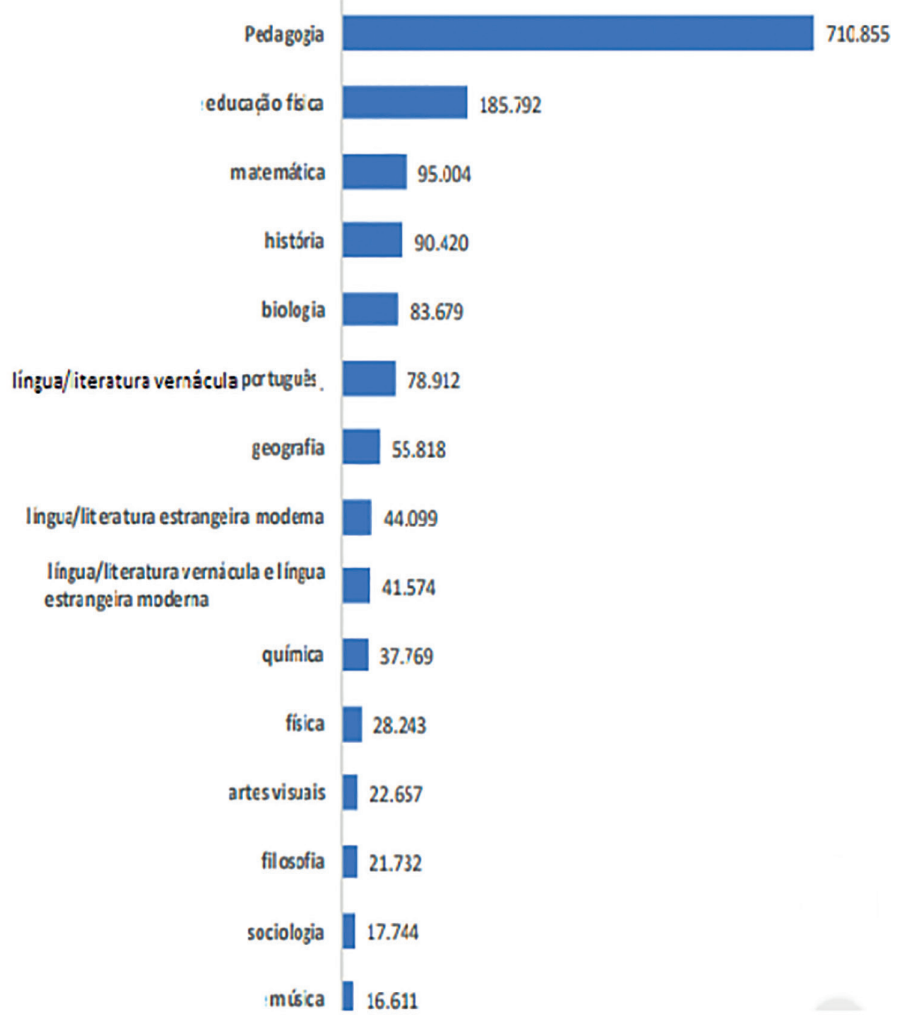

Fonte: INEP (2017).

Figura 3 - Grau acadêmico.

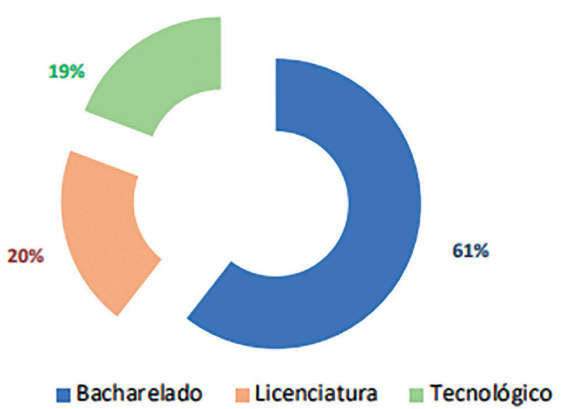

Fonte: INEP (2017). 
Figura 4 - Perfil de estudantes.

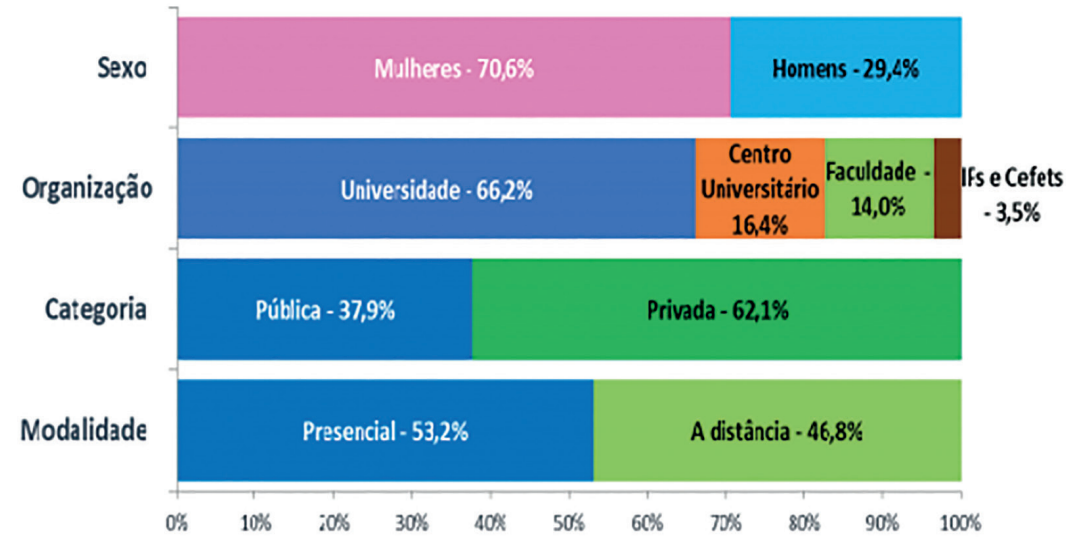

Fonte: INEP (2017).

A Base Nacional Comum Curricular (BNCC), por exemplo, prevê que os estudantes devem desenvolver competências cognitivas e socioemocionais para sua formação ao longo da Educação Básica (Figura 5).

Figura 5 - Competências gerais na nova BNCC.

\section{COMPETÊNCIAS GERAIS DA NOVA BNCC}

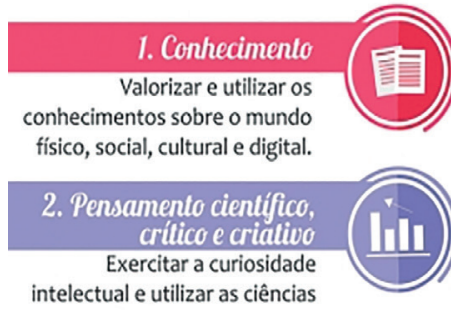

intelectual e utilizar as ciências com criticidade e criatividade.

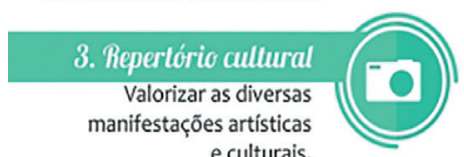
e culturais.
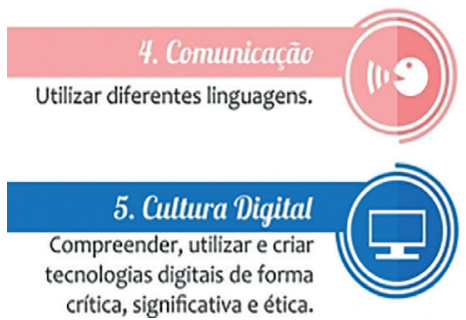

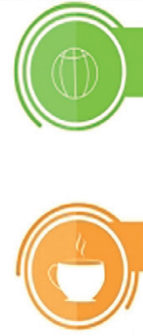

10. Responsabilidade e Cidadania

Agir pessoal e coletivamente com autonomia, responsabilidade, flexibilidade, resiliência e determinação.

9. Empatia e Cocperacióo

Exercitar a empatia, o diálogo, a resoluçăo de conflitos e a cooperação.
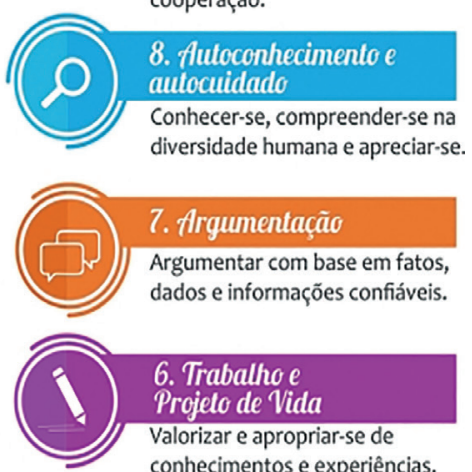

6. Trabalhoe

Projelo de Vida

Valorizar e apropriar-se de conhecimentos e experiências.

Fonte: INEP (s/d). 
Evidentemente, ao se saber o que alunos na Educação Básica deverão desenvolver como competências, há indicativos claros de competências a serem trabalhadas por professores em formação, posto que não se pode ensinar o que não se sabe. É importante salientar que os documentos publicados recentemente no Brasil, DCE, PNE e BNCC, alinham-se com o que se espera internacionalmente em termos de propostas para a educação. Dessa forma, resta questionar: por que então os resultados tão negativos e o reconhecimento de que é preciso "dar um cavalo de pau" no que se tem como Educação Básica e formação de professores na Educação Superior?

\section{Algumas possibilidades para repensar a formação}

E é pensando na construção de uma nova sociedade e nas possíveis respostas às questões postas ao longo do texto que se depara com instituições de Educação Superior que até hoje não conseguiram encontrar respostas aos problemas da atualidade. Diante dessa conjuntura, há uma expectativa, que não é só da sociedade brasileira, mas mundial, de que a educação se posicione na linha de frente na luta contra as exclusões, contribuindo para a promoção e a integração de todos os brasileiros, voltando-se à formação da cidadania, não como meta a ser atingida em um futuro distante, mas como prática efetiva no momento presente.

No tocante às possibilidades para se refletir sobre a formação para a docência necessária a esse novo contexto, há que se fortalecer:

- Princípio do regime de colaboração - União, redes de ensino, instituições formadoras.

- Visão sistêmica - articulação das IES com as escolas de Educação Básica.

- Domínio dos conhecimentos previstos na BNCC.

- Articulação entre teoria e prática - interdisciplinaridade, interculturalidade e inovação.

- Formação humana e integral.

Ainda nessa perspectiva, há que se observar a imprescindibilidade de compreender que as tecnologias digitais modificaram as formas de ensinar e aprender, mas a "revolução" a ser feita não é apenas na didática. Ela é HUMANA! As tecnologias estarão presentes em qualquer cenário futuro em que possam ser utilizadas para tornar o mundo melhor. Mas quem as utiliza são as pessoas. São as pessoas que lhes dão vida... Assim como um livro não tem valor em uma estante, as tecnologias não têm valor se mal utilizadas.

Não basta, desta feita, alterar matrizes curriculares se os professores formadores continuarem a ensinar com faziam antes; não basta inserir ferramentas tecnológicas se não ampliar a postura para atuar em rede; não basta dizer nos 
planos de ensino que as aulas são dialogadas se não se abrir para a comunidade em que se está inserido e para uma escuta ativa dos alunos que estão aprendendo com professores formadores a melhor maneira de ser professor...

É preciso ainda desmistificar a educação como missão de leigos que amam as crianças e, em um movimento de doação de vida, vão lhes passar tudo o que sabem. Chega de romantizar a docência. Há que se profissionalizar a docência. A Pedagogia não é dom. É conhecimento! É urgente tratar a educação e suas licenciaturas como ciência e ressignificar os cursos de forma a incorporar as dinâmicas dos currículos da Educação Básica. Sem esse alinhamento, as mudanças não serão possíveis. O Papa Francisco, em uma de suas belas falas, ensina que uma educação do humanismo solidário desenvolve redes de cooperação nos distintos âmbitos em que se realiza a atividade educativa.

Essa nova postura exige a formação de professores-sujeitos em um paradigma diferenciado que se distancia do paradigma vigente: racional, cartesiano. É nesse cenário que os processos educativos precisam ser refletidos, repensados, ressignificados, reinventados. Para se construir esse espaço de inovação e de ruptura, é preciso que se tenha claro que a aprendizagem se constitui mais como processo de transformação do que mera acumulação de conteúdos descontextualizados.

Destarte, nenhum processo de formação docente pode se reduzir à mera atividade de transmitir fórmulas e receitas ou reproduzir filosofias prontas. Há que se ir adiante, articulando pensamento crítico, estudo da realidade, problematização e proposição de soluções. São os docentes os protagonistas dessa mudança e não é possível se furtar a essa responsabilidade já.

\section{Considerações finais}

A urgência de se repensar a docência exige mais que mudanças curriculares; o esforço a ser realizado requer que as instituições abram espaços para repensar, de forma estratégica, as formas de ensinar e aprender, diante das questões emergentes de um mundo em constante mudanças. Contudo, faz-se necessário que o olhar no futuro, mergulhado em tecnologias, não perca de vista a dimensão humana.

É premente a mudança de paradigmas nas novas maneiras de ensinar e aprender que precisam contemplar um processo mais compartilhado, mediado pelo docente, com foco nas individualidades e na interação coletiva, colocando o estudante no centro, em que o papel das tecnologias seja periférico no sentido de permear todos os cenários educacionais, valorizando e privilegiando a perspectiva do professor como "referência humana".

Recebido em: 19/08/2019

Aceito para publicação em: 21/09/2019 


\section{Notas}

1 Possui graduação em Pedagogia pela Associação de Ensino Unificado do Distrito Federal. Graduação em Administração pela Universidade Católica de Brasília (UCB). Especialização em Gestão Educacional, em Gestão de Pessoas e em EaD pela Universidade de Brasília (UnB). Mestrado em Tecnologia da Informação e Comunicação pela Universidade Federal do Ceará. Foi diretora pedagógica do Colégio INEI - Instituto de Educação Integral, durante o período de 1980 a 1993 (Educação Básica). Diretora da Faculdade ICESP (2007 a 2015). Analista de projetos em EaD no SESI. Atua na UCB onde já assumiu os cargos de coordenadora dos cursos de Pedagogia, Gestão de Recursos Humanos e Psicopedagogia. É doutoranda em Ciências da Educação. Atualmente ocupa o cargo de diretora da escola de Educação, Tecnologia e Comunicação da UCB. E-mail: anelisep@ucb.br

2 Mestre em Educação pela Universidade de Brasília (UnB). Especialista em Linguagem e Educação pela Fundação Brasileira de Teatro. Pedagoga com habilitação em Tecnologia Educacional pela UnB (1985) e Administração Escolar pela UnB (1986). Professora da Universidade Católica de Brasília (UCB). Consultora pedagógica da área de segurança pública e colaboradora do comitê internacional da Cruz Vermelha no programa de direitos humanos para policiais. E-mail: bernadete@ucb.br

3 Possui graduação em Letras pelo Centro de Ensino Unificado de Brasília (1986). Especialização em Administração Escolar e em Educação a Distância e Mestrado em Educação pela Universidade Católica de Brasília (UCB) (2001). Atualmente, é professora e coordenadora geral acadêmica da UCB. Atua ainda como conteudista e professora em cursos de graduação e pós-graduação. É ainda escritora de livros infantis. E-mail: sandra.bessa@ucb.br

\section{Referências}

ALVAREZ, Luciana. PNE - Diferenças entre o previsto e o realizado. Revista Educação, 5 ago. 2016. Disponível em: https://www.revistaeducacao.com.br/ pne-diferencas-entre-o-previsto-e-o-realizado/. Acesso em: 11 ago. 2019.

BRASIL. Ministério da Educação. Planejando a próxima década: conhecendo as 20 metas do Plano Nacional de Educação. Brasília: MEC, 2014. Disponível em: http://pne.mec.gov.br/images/pdf/pne_conhecendo_20_metas.pdf. Acesso em: 11 ago. 2019.

FRANÇA, Luísa. BNCC: tudo que você precisa saber sobre a Base Nacional Comum Curricular. Par Plataforma Educacional, 28 fev. 2019. Disponível: https://www.somospar.com.br/bncc-base-nacional-comum-curricular/. Acesso em: 13 ago. 2019.

GATTI, Bernardete. Didática e formação de professores: provocações. Caderno de Pesquisa, v. 47, n. 166, p. 1150-1164, 2017. Disponível em: http://www.scielo.br/pdf/cp/v47n166/1980-5314-cp-47-166-1150.pdf. Acesso em: 10 ago. 2019.

GOT'TI, Alessandra. Mozart Neves: "Sem bons professores, não avançaremos". Revista Nova Escola, 29 jul. 2019. Disponível em: https://novaescola. 
org.br/conteudo/18132/mozart-neves-sem-bons-professores-nao-avancaremos\#. Acesso em: 10 ago. 2019.

IBOPE INTELIGÊNCIA. Todos Pela Educação. Itaú Social. Profissão Professor. jul. 2018. Disponível em: https://www.todospelaeducacao.org.br/_ uploads/_posts/23.pdf?750034822. Acesso em: 11 ago. 2019.

INEP - Instituto Nacional de Estudos e Pesquisas Educacionais Anísio Teixeira. Censo da Educação Superior: notas estatísticas 2017. Brasília: INEP, 2017. Disponível em: http://download.inep.gov.br/educacao_superior/censo_superior/documentos/2018/censo_da_educacao_superior_2017-notas_estatisticas2.pdf. Acesso em: 10 jul. 2019.

. Novas competências da Base Nacional Comum Curricular. s/d. Disponível em: http://inep80anos.inep.gov.br/inep80anos/futuro/novas-competencias-da-base-nacional-comum-curricular-bncc/79. Acesso em: 10 de jul. 2019.

MONFREDINI, Ivanise (Org.). Universidade como espaço de formação de sujeitos. Santos: Editora Universitária Leopoldianum, 2016.

OCDE - Organização para Cooperação e Desenvolvimento Econômico. Learning Compass 2030. Disponível em: https://www.oecd.org/education/ 2030-project/teaching-and-learning/learning/. Acesso em: 11 ago. 2019.

ONU - Organização das Nações Unidas. Agenda 2030. Nova Iorque, set. 2015. Disponível em: https:// nacoesunidas.org/pos2015/agenda2030/. Acesso em: 11 ago. 2019.

PLATAFORMA AGENDA 2030. A Agenda 2030 para o Desenvolvimento Sustentável. s/d. Disponível em: http://www.agenda2030.org.br/sobre/. Acesso em: 11 ago. 2019.

ROGGERO, Rosemary. A educação superior na contemporaneidade - Notas para pensar a formação do sujeito. In: CONGRESSO INTERNACIONAL DE EDUCAÇÃO, 12., 2015, Curitiba. Anais... Curitiba: PUC-PR, 2015. Disponível em: https://educere.bruc.com.br/arquivo/pdf2015/20111_7955.pdf. Acesso em: 11 ago. 2019.

UNESCO - Organização das Nações Unidas para a Educação, a Ciência e a Cultura. Educação 2030: Declaração de Incheon e Marco de Ação, rumo a uma educação de qualidade inclusiva e equitativa e à educação ao longo da vida para todos. Brasília, 2016. Disponível em: https:/ / unesdoc.unesco.org/ ark:/48223/pf0000243278_por. Acesso em: 11 ago. 2019. 